\section{Q312: Biotech on a roll}

\section{Walter Yang}

Biotech continued to outperform the broader markets, with the BioCentury 100 Index up 7\% and the NASDAQ Biotechnology Index up $10 \%$ in 3Q12 versus a $6 \%$ rise in the S\&P 500. Excluding partnership monies, the industry raised (mostly from debt and follow-on offerings)

\section{Stock market performance}

In 3Q12, the BioCentury 100 was up 7\% and the NASDAQ Biotechnology was up $10 \%$.

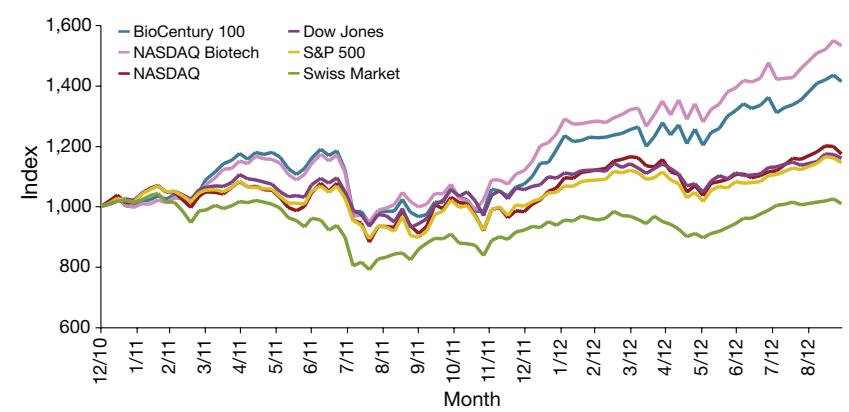

Notable $3 Q 12$ deals

\begin{tabular}{|c|c|c|c|c|c|}
\hline \multicolumn{2}{|l|}{$\begin{array}{l}\text { Company (lead } \\
\text { underwriters) }\end{array}$} & \multicolumn{2}{|c|}{$\begin{array}{l}\text { Amount raised } \\
\text { (\$ millions) }\end{array}$} & $\begin{array}{l}\text { Change in stock } \\
\text { price since offer }\end{array}$ & $\begin{array}{c}\text { Date } \\
\text { completed }\end{array}$ \\
\hline \multicolumn{2}{|c|}{$\begin{array}{l}\text { Durata (BofA Merrill Lynch; Credit } \\
\text { Suisse) }\end{array}$} & & 77.6 & $4 \%$ & 19-Jul \\
\hline \multicolumn{2}{|c|}{ Hyperion (Leerink; Cowen) } & & 57.5 & $6 \%$ & 26-Jul \\
\hline \multicolumn{2}{|c|}{ PharmaEngine (MasterLink) } & & 31.7 & $108 \%$ & 18-Sep \\
\hline \multicolumn{2}{|l|}{ Clinigen (Numis) } & & 16.2 & $10 \%$ & 19-Sep \\
\hline \multicolumn{6}{|l|}{ Venture capital } \\
\hline \multicolumn{2}{|l|}{$\begin{array}{l}\text { Company (lead } \\
\text { investors) }\end{array}$} & \multicolumn{2}{|c|}{$\begin{array}{l}\text { Amount raised } \\
\text { (\$ millions) }\end{array}$} & Round number & Date closed \\
\hline \multicolumn{2}{|c|}{ CureVac (dievini Hopp) } & & 105 & 4 & 18-Sep \\
\hline \multicolumn{2}{|c|}{$\begin{array}{l}\text { bluebird bio (Deerfield; RA Capital; } \\
\text { Ramius)a }\end{array}$} & & 60 & 4 & 25-Jul \\
\hline \multicolumn{2}{|l|}{ CardioDx (Temasek) } & & 58 & 6 & 27-Aug \\
\hline \multicolumn{2}{|l|}{ Onconovab } & & 50 & ND & 13-Aug \\
\hline \multicolumn{2}{|l|}{ Relypsa $a^{b, c}$} & & 50 & 3 & 10-Aug \\
\hline \multicolumn{2}{|c|}{ Histogenics (Sofinnova) } & & 49 & 1 & 24-Jul \\
\hline \multicolumn{2}{|c|}{ Foundation Medicine $e^{b}$} & & 43 & 2 & 20-Sep \\
\hline \multicolumn{2}{|c|}{ Agile Therapeutics (Aisling) } & & 40 & 3 & 19-Jul \\
\hline \multicolumn{6}{|c|}{ Mergers and acquisitions } \\
\hline \multicolumn{2}{|l|}{ Target } & \multicolumn{2}{|c|}{ Acquirer } & $\begin{array}{c}\text { Value }^{\mathrm{d}} \\
(\$ \text { millions })\end{array}$ & Date announced \\
\hline \multicolumn{2}{|c|}{ Elevation Pharmaceuticals } & \multicolumn{2}{|c|}{ Dainippon Sumitomo } & 430 & 31-Aug \\
\hline \multicolumn{2}{|l|}{ Complete Genomics } & \multicolumn{2}{|c|}{ BGI-Shenzhen } & 118 & 17-Sep \\
\hline \multicolumn{2}{|c|}{ Callisto Pharmaceuticals } & \multicolumn{2}{|c|}{$\begin{array}{l}\text { Synergy } \\
\text { Pharmaceuticals }\end{array}$} & 117 & 20-Jul \\
\hline \multicolumn{2}{|l|}{ CNS Therapeutics } & Covidien & & 100 & 24-Sep \\
\hline \multicolumn{6}{|c|}{ Licensing/collaboration } \\
\hline Researcher & Investor & $\begin{array}{c}\text { Value }^{\mathrm{d}} \\
\text { (\$ millions) }\end{array}$ & Deal desc & & \\
\hline Molecular Partners & Allergan & 1,463 & $\begin{array}{l}\text { Rights to pr } \\
\text { compound I } \\
\text { ankyrin repe }\end{array}$ & $\begin{array}{l}\text { nical wet age-related } m \\
260 \text {; three options to } \\
\text { oroteins (DARPins) in o }\end{array}$ & $\begin{array}{l}\text { cular degeneration } \\
\text { cense designed } \\
\text { hthalmology }\end{array}$ \\
\hline Genmab & $\begin{array}{l}\text { Johnson \& } \\
\text { Johnson }\end{array}$ & 1,135 & $\begin{array}{l}\text { Rights to de } \\
\text { daratumum } \\
\text { antibody ( } m\end{array}$ & $\begin{array}{l}\text { p and commercialize } \\
\text { HuMax-CD38), a huma } \\
\text { against CD38 in phase }\end{array}$ & $\begin{array}{l}\text { incer product } \\
\text { monoclonal } \\
1 / 2\end{array}$ \\
\hline Macrogenics & Servier & 1,100 & $\begin{array}{l}\text { Option to lic } \\
\text { undisclosed } \\
\text { Korea and I }\end{array}$ & $\begin{array}{l}\text { e rights to preclinical } \\
\text { ncer targets outside No }\end{array}$ & $\begin{array}{l}\text { Abs against three } \\
\text { h America, Japan, }\end{array}$ \\
\hline Symphogen & Merck KGaA & 623 & $\begin{array}{l}\text { Rights to ph } \\
\text { two anti-EG }\end{array}$ & $\begin{array}{l}2 \text { cancer product Sym } \\
\text { mAbs against two disti }\end{array}$ & $\begin{array}{l}\text { 04, a combination of } \\
\text { ct epitopes }\end{array}$ \\
\hline Onconova & Baxter & 565 & $\begin{array}{l}\text { European ri } \\
\text { of phosphoi } \\
\text { phase } 3 \text { for }\end{array}$ & $\begin{array}{l}\text { to commercialize rigo } \\
\text { tide } 3 \text {-kinase and polo } \\
\text { lodysplastic syndrome }\end{array}$ & $\begin{array}{l}\text { ertib, a dual inhibitor } \\
\text { like kinase } 1 \text { in }\end{array}$ \\
\hline Regulus & AstraZeneca & 537 & $\begin{array}{l}\text { Develop and } \\
\text { therapeutic: } \\
\text { and metabo }\end{array}$ & $\begin{array}{l}\text { mmercialize preclinica } \\
\text { ainst three targets focu } \\
\text { diseases and cancer }\end{array}$ & $\begin{array}{l}\text { microRNA } \\
\text { ed on cardiovascular }\end{array}$ \\
\hline
\end{tabular}

$\$ 13$ billion last quarter-the fourth highest of any quarter since 2000. Only four companies completed initial public offerings (IPOs). About $\$ 1.8$ billion was raised by private biotechs, up from $\$ 1.4$ billion in $2 \mathrm{Q} 12$ and $\$ 1.4$ billion a year ago.

\section{Global biotech industry financing}

Excluding partnerships, biotechs raised $\$ 13$ billion.

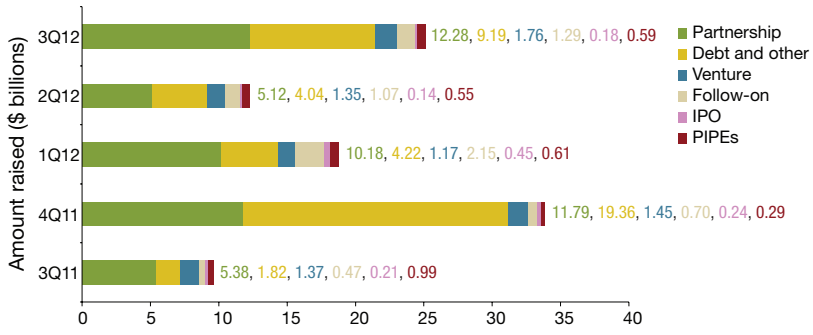

Source: $B C I Q$ : BioCentury Online Intelligence, Burrill \& Co. PIPEs, private investments in public equity.

\section{Global biotech initial public offerings}

IPOs continue to trickle in, with only four companies raising $\$ 183.1$ million.
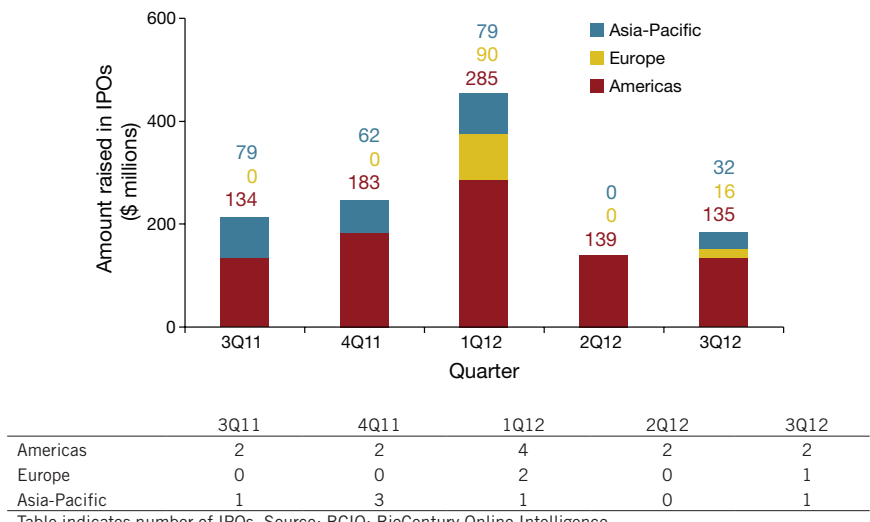

Table indicates number of IPOs. Source: BCIQ: BioCentury Online Intelligence.

\section{Global biotech venture capital investment}

Private biotechs raised $\$ 1.7$ billion in 3Q12, up from $\$ 1.4$ billion a year ago.
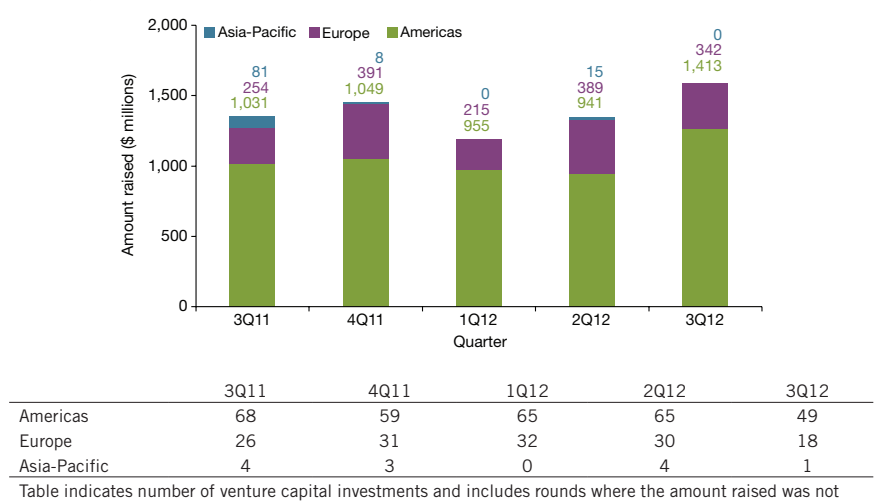
disclosed.

Source: $\mathrm{BCIQ}$ : BioCentury Online Intelligence.

Walter Yang is Research Director at BioCentury. 